\title{
Use of growth inhibitor chlormequat chloride in potato culture in vitro
}

\author{
Sergey A. Buldakov * \\ Sakhalin Research Institute of Agriculture, Yuzhno-Sakhalinsk, 963022, Russian Federation
}

\begin{abstract}
The publication presents data on the use of growth inhibitor chlormequat chloride in in vitro potato culture on varieties of different maturity groups: Meteor (early), Zekura (mid-early), and Northern Lights (mid-season). Five dosages of the investigational product were studied, ranging from 0.1125 to $1.8 \mathrm{~g} / \mathrm{l}$. It was found that in maximum doses of the product there was a strong inhibition of all growth processes in all varieties. The research results showed that the most optimal concentration of chlormequat chloride is $0.225 \mathrm{~g}$ per 1 liter of Murashige and Skoog medium. At this dose, on $30^{\text {th }}$ day of cultivation, there was a decrease in the height of microplants from the control by $63.2-85.1 \%$, in the root length - up to $15.0 \%$ and their number - up to $22.8 \%$ and an increase in the number of internodes by 6.5-22,0 \% depending on the variety. The investigational product had an effect on formation of microtubers; in the Meteor variety, their largest number was $89.5 \%$ in the nutrient medium with a dose of $1.8 \mathrm{~g} / \mathrm{l}$, in the Zekura variety - 93.0\% in the nutrient medium with a dose of $0.9 \mathrm{~g} / \mathrm{l}$. The new technique makes it possible to lengthen the periods between cuttings of test-tube plants by 2.3 times. This, in turn, reduces the cost of maintaining the in vitro collection material of potatoes in the summer-autumn period, and improves its quality, since each additional cutting cycle affects a more rapid degeneration of the variety. Also, microplants grown with growth inhibitor during subsequent relocation to a standard Murashige and Skoog medium did not show an aftereffect.
\end{abstract}

\section{Introduction}

Currently, for implementation of seed-growing programs in Russia, in vitro potato culture is used, which is mass-produced in biotechnological laboratories. At the same time, the original microplants are obtained from the bank of healthy potato varieties, where varietal lines are updated annually, using methods of selection and introduction into in vitro culture with multilevel testing for latent phytopathogens [1, 2].

Modern technologies and regulations for obtaining in vitro culture recommend organizations producing source material to update their collections of varieties every 2 years and during this time to carry out not more than 10 cuttings to preserve the quality of test-tube potatoes $[3,4,5]$. To achieve this indicator, modified nutrient media with mixtures

\footnotetext{
* Corresponding author: sarsarsar88@mail.ru
} 
of growth stimulants are used, and the period between passages is also lengthened by temperature regulation [6]. Considering that biotechnological laboratories have two stages of work: the first is mass replication of microplants in the winter-spring period, and the second is maintenance of collection material in small volumes in the summer-autumn period. Therefore, optimization to reduce the number of cuttings at the second stage of work in biological laboratories is an urgent direction. Since the reduction of passages will not only improve the quality of the source material, but also reduce the overall cost. For this purpose, it is promising to use substances inhibiting growth, which are both natural (phenolic and terpenoid compounds) and synthetic (antagonists of auxin transport, retardants, morfactins, paralyzers) [7, 8].

Among the inhibitors, retardants (substances that inhibit stem growth) have found widespread use on potatoes, of which the most studied drug TUR (chlorocholine chloride, chlormequat chloride) is a white hygroscopic crystalline substance, readily soluble in water and alcohol, and low toxic. According to literature data, spraying potato plants with TUR reduces the growth of stems, the length of internodes, increases the number of leaves and their size, reduces the length of stolons and accelerates tuberization [9, 10, 11]. Given the properties of chlormequat chloride, this substance can be used with high efficiency in in vitro potato culture to suppress the growth of microplants and, accordingly, to lengthen the period between passages.

The purpose of this work was to determine optimal concentrations of chlormequat chloride for growth processes in a test tube culture of potatoes in different maturity groups.

\section{Materials and methods}

The studies were carried out at FSBSI 'Sakhalin Research Institute of Agriculture' in 2020. During the year, a series of experiments was conducted to study the effect of various concentrations of chlormequat chloride (abbreviated as CCC) on potato varieties of different maturity groups: early (Meteor), mid-early (Zekura), mid-season (Northern Lights). The comparison was carried out with a standard Murashige and Skoog medium (abbreviated - MS0). The experimental scheme consisted of 6 options:

1 MS0 nutrient medium (control);

2 MS0 nutrient medium with $1.8 \mathrm{~g} / \mathrm{l}$ of CCC;

3 MS0 nutrient medium with $0.9 \mathrm{~g} / \mathrm{l}$ of CCC;

4 MS0 nutrient medium with $0.45 \mathrm{~g} / \mathrm{l}$ of CCC;

5 MS0 nutrient medium with $0.225 \mathrm{~g} / \mathrm{l}$ of CCC;

6 MS0 nutrient medium with $0.1125 \mathrm{~g} / \mathrm{l}$ of CCC.

In laboratory conditions, test tube plants were cut into segments, a stalk with a leaf. For greater uniformity, when setting up the experiment, the lower stalk and the top of the microplant were excluded. Tubes with stalks were placed in a phytotron. Growing conditions: temperature of $21-23{ }^{\circ} \mathrm{C}$, intensity of illumination - up to 5 thousand lux, photoperiod of 16-17 hours.

Laboratory experiments on in vitro potato culture were carried out according to the methodological manual by S.N. Timofeeva and others [12].

Mathematical processing of experimental results was carried out according to B.A. Dospekhov [13]. 


\section{Results and discussion}

Studies showed that the use of a growth inhibitor when added to the nutrient medium had a significant effect on the growth processes in microplants of all studied varieties in in vitro culture (Table 1$)$.

Table 1. The effect of chlormequat chloride on biometrics of potato microplants on $30^{\text {th }}$ day of cultivation.

\begin{tabular}{|c|c|c|c|c|c|c|c|c|}
\hline Option & $\begin{array}{c}\text { Plant } \\
\text { height, } \\
\text { cm }\end{array}$ & $\begin{array}{c} \pm \text { to } \\
\text { contr } \\
\text { ol,\% }\end{array}$ & $\begin{array}{c}\text { Number } \\
\text { of } \\
\text { internode } \\
\text { s, pcs. }\end{array}$ & $\begin{array}{c} \pm \text { to } \\
\text { contr } \\
\text { ol,\% }\end{array}$ & $\begin{array}{c}\text { Root } \\
\text { length, } \\
\text { cm }\end{array}$ & $\begin{array}{c} \pm \text { to } \\
\text { contr } \\
\text { ol,\% }\end{array}$ & $\begin{array}{c}\text { Number } \\
\text { of roots, } \\
\text { pcs. }\end{array}$ & $\begin{array}{c} \pm \text { to } \\
\text { contr } \\
\text { ol,\% }\end{array}$ \\
\hline \multicolumn{7}{|c|}{ Meteor } \\
\hline 2 & 11.78 & 0 & 6.80 & 0 & 4.19 & 0 & 10.30 & 0 \\
\hline 3 & 0.69 & -94.1 & 4.63 & -31.9 & - & - & - & - \\
\hline 4 & 0.94 & -92.0 & 7.33 & +7.8 & 1.46 & -65.2 & 0.78 & -92.4 \\
\hline 5 & 1.18 & -90.0 & 7.89 & +16.0 & 3.32 & -20.8 & 6.78 & -34.2 \\
\hline 6 & 1.75 & -85.1 & 8.30 & +22.1 & 3.56 & -15.0 & 8.30 & -19.4 \\
\hline $\mathrm{HCP}_{0.5}$ & 0.8 & - & 0.7 & - & 0.5 & - & 1.0 & - \\
\hline \multicolumn{7}{|c|}{ Zekura } \\
\hline 1 & 10.65 & 0 & 8.40 & 0 & 4.54 & 0 & 6.70 & 0 \\
\hline 2 & 0.57 & -94.6 & 5.22 & -37.9 & - & - & - & - \\
\hline 3 & 0.75 & -93.0 & 6.00 & -28.6 & 0.90 & -80.2 & 0.60 & -91.0 \\
\hline 4 & 1.40 & -86.9 & 7.55 & -10.1 & 3.50 & -22.9 & 3.00 & -55.2 \\
\hline 5 & 2.22 & -79.2 & 8.95 & +6.5 & 4.98 & +9.7 & 5.17 & -22.8 \\
\hline 6 & 3.90 & -63.4 & 9.15 & +8.9 & 5.35 & +17.8 & 5.63 & -16.0 \\
\hline $\mathrm{HCP}_{0.5}$ & 0.8 & - & 0.5 & - & 0.6 & - & 0.9 & - \\
\hline \multicolumn{7}{|c|}{ Northern Lights } & & \\
\hline 1 & 9.82 & 0 & 10.90 & 0 & 5.37 & 0 & 8.10 & 0 \\
\hline 2 & 0.80 & -91.9 & 8.40 & -22.9 & 4.20 & -21.8 & 4.60 & -43.2 \\
\hline 3 & 1.14 & -88.4 & 10.80 & -0.9 & 5.86 & +9.1 & 7.60 & -6.2 \\
\hline 4 & 1.71 & -82.6 & 11.40 & +4.6 & 5.80 & +8.0 & 8.30 & +2.5 \\
\hline 5 & 3.61 & -63.2 & 12.10 & +11.0 & 5.66 & +5.4 & 8.20 & +1.2 \\
\hline 6 & 5.13 & -47.8 & 10.80 & -0.9 & 5.53 & +3.0 & 6.80 & -16.0 \\
\hline $\mathrm{HCP}_{0.5}$ & 0.7 & - & 0.7 & - & 0.5 & - & 1.0 & - \\
\hline
\end{tabular}

Chlormequat chloride reduced the height of test-tube plants depending on the concentration - by $47.8-94.6 \%(4.7-11.1 \mathrm{~cm})$. The greatest effect in this indicator was achieved at the maximum dose $(1.8 \mathrm{~g} / \mathrm{l})$; under its action, a very strong inhibition of planted stalks was observed in all varieties. A twofold decrease in the investigational product (0.9 $\mathrm{g} / \mathrm{l})$ increased the average plant height from the maximum concentration by $1.6-3.5 \%$, a fourfold decrease $(0.45 \mathrm{~g} / \mathrm{l})$ - by $4.1-9.3 \%$, an eightfold decrease $(0.225 \mathrm{~g} / \mathrm{l})$ - by $9.0-28.7 \%$, respectively. It was also noted that the maturity group of varieties affects the response to the action of chlormequat chloride. For example, the early variety Meteor is more sensitive to the active ingredient, since even at low concentrations $(0.1125 \mathrm{~g} / \mathrm{l})$ it showed the greatest decrease in plant height $(8.6 \mathrm{~cm})$ compared to the medium early variety Zekura $(6.8 \mathrm{~cm})$ and the mid-season variety Northern Lights $(4.7 \mathrm{~cm})$.

The number of internodes is considered an important indicator, since the multiplication factor - the ratio of the number of microplants before cutting to the number of grown 
microplants in one cycle, depends on it; that is, the number of cuttings that can be obtained from a plant is equal to the number of internodes. This indicator is significant, since it enables you to quickly multiply genetically valuable material in in vitro culture [6].

A typical feature of early and mid-early varieties when grown in in vitro culture is their rapid elongation in a test tube to a cork. At the same time, despite their impressive stem length, the number of stalks obtained is less than that of later varieties. The research results showed that when a retardant is added in large doses, the number of internodes decreases (22.9-39.3\%), and they become crowded. As chlormequat chloride decreases, the number of internodes increases and reaches its maximum value in the early Meteor variety (54.4\%) and the mid-early Zekura variety (6.4\%) at the lowest product concentration $(0.1125 \mathrm{~g} / \mathrm{l})$. For the mid-season variety Northern Lights, the peak value is recorded at a dose of 0.225 $\mathrm{g} / \mathrm{l}$, which corresponds to an increase in internodes by $11 \%$ of the control value. A universal concentration suitable for all varieties of different maturity groups can be considered a dose of $0.225 \mathrm{~g}$ of chlormequat chloride per liter of nutrient medium, since under its action there is a significant increase in the number of internodes by 6.5-22.0\% depending on the variety.

A well-developed root system plays an important role in the adaptation of test-tube plants to the soil substrate, thanks to which the plants take root faster in external conditions. It can be seen from the data presented that the growth inhibitor influenced rhizogenesis of test-tube plants. A high dose of the product (1.8 g/l) completely stopped the growth of the root system in all varieties. At the same time, a small amount of the active substance had a multidirectional effect, which strongly depended on varietal responsiveness. For potatoes of Meteor and Northern Lights varieties, all concentrations of chlormequat chloride had a depressing effect on the root system, reducing its length to 65.2 and $30.8 \%$ and the number of roots to 92.4 and $43.2 \%$, respectively; only in small doses $(0.225 \mathrm{~g} / \mathrm{l}$ and $0.1125 \mathrm{~g} / \mathrm{l})$ indicators were within the control value. Root formation in Zekura variety was the most sensitive to chlormequat chloride, since high doses of the product $(0.9 \mathrm{~g} / \mathrm{l})$ more strongly reduced the length of roots by $80.2 \%$, while the lowest concentration of the active substance $(0.1125 \mathrm{~g} / \mathrm{l})$ increased root size to the maximum by $17.8 \%$ compared to other varieties.

Considering the studied indicators and varietal responsiveness to the action of different concentrations of chlormequat chloride, the optimal dose is $0.225 \mathrm{~g} / \mathrm{l}$, as in this option microplants grow compact $(1.75-3.61 \mathrm{~cm})$ with many internodes $(8.3-12,1)$ and a sufficiently developed root system. Such indicators contribute to the long standing of testtube plants and, accordingly, lengthening of the inter-interval period of cuttings. Also, based on observations, chlormequat chloride in the established concentrations increased the size of leaf blades and made them dark green in color. No other morphological changes in the shape and pubescence of leaves were observed in potato microplants (Figure 1).

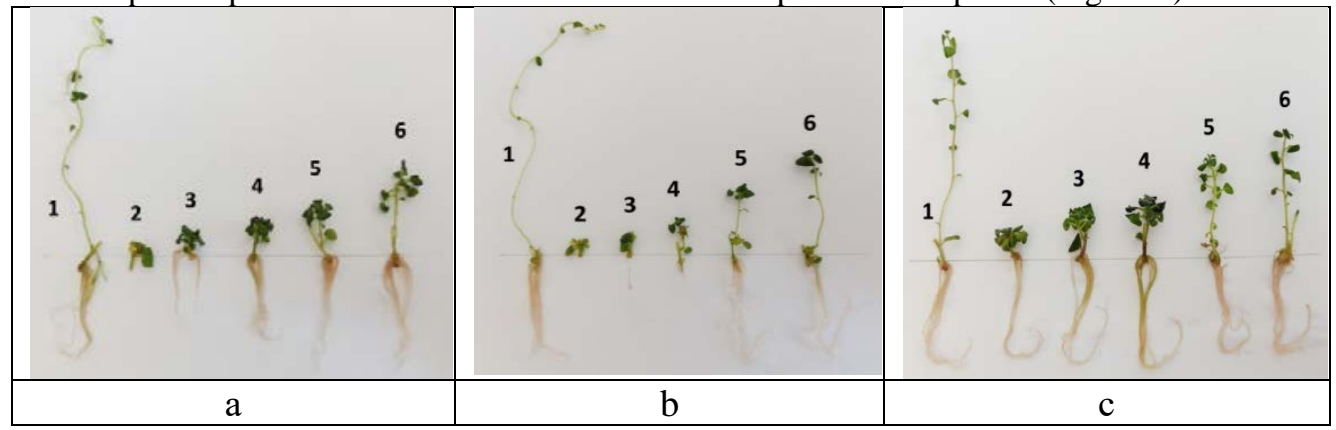

Fig. 1. Appearance of test-tube plants of potato culture (a - Meteor variety; b - Zekura variety; c Northern Lights variety). 
The next stage in the development of microplants is formation of microtubers. This process is associated with the removal of apical dominance and, accordingly, inhibition of axial growth. It is known that the tuber is formed due to periclinal divisions of stem cells located below the apex. Reorientation of cell divisions from synclinal to periclinal occurs due to the flow of metabolites of general metabolism and phytohormones into this part of the stem. Efficiency of microtubing depends on factors such as temperature, light, photoperiod, and also on varietal characteristics of plants [14].

According to our data, formation of microtubers depended on the maturity group of the variety and concentration of the growth inhibitor. The early Meteor variety began to form microtubers on $40^{\text {th }}$ day, their largest number and size were observed at the maximum dose of chlormequat chloride - 89.5\% and $3.2 \mathrm{~mm}$ and decreased with a decrease in the active ingredient: 0.9 g/l - 27, 0\% and 3 mm, 0.45 g/l - 15.7\% and $2.7 \mathrm{~mm}$. During control period, the number of tubers was $9.5 \%$, and their size reached $2 \mathrm{~mm}$. At the same time, at doses of $0.225 \mathrm{~g} / \mathrm{l}$ and $0.1125 \mathrm{~g} / \mathrm{l}$ of the retardant microtubers were absent on the day of observation. Chlormequat chloride had a significant effect on the induction of microtubers in the midseason Zekura variety, the highest rates were observed at a dose of $0.9 \mathrm{~g} / \mathrm{l}-93.0 \%$ with an average size of microtubers of $3.9 \mathrm{~mm}$. A gradual decrease in the concentration of the product reduced the indicators: $0.45 \mathrm{~g} / \mathrm{l}-89.5 \%$ and $3.5 \mathrm{~mm}, 0.225 \mathrm{~g} / \mathrm{l}-85.0 \%$ and $3.6 \mathrm{~mm}$, $0.1125 \mathrm{~g} / \mathrm{l}-76.5 \%$ and $3.6 \mathrm{~mm}$, respectively. The control contained the smallest number of microplants with microtubers - $16.5 \%$. On 40th day of cultivation in test-tube plants of the mid-season Northern Lights variety, microtubulation was not observed in all options. The retardant also influenced the method of setting microtubers; in all options with its action, tubers were formed on the stem in the leaf axils; in the control options, microtubers grew on stolons in a nutrient medium near the roots.

Subsequent observations of an isolated experiment option on safety of microplants showed that on 60th day after the passage, control microplants filled the entire test tube space, twisted under the stopper and died from use of the entire volume of the nutrient medium. In the second month, plants with chlormequat chloride $(0.225 \mathrm{~g} / \mathrm{l})$ were viable, vigorous, they increased in growth by an average of $1.0-1.3 \mathrm{~cm}$ and reached half the volume of the test tube, while the amount of unused nutrient medium remained within 30$35 \%$ of the original volume. Further maintenance of microplants in a modified nutrient medium showed the possibility of lengthening the period between cuttings up to 70 days (2.3 times more than with the standard reproduction scheme). Also, microplants grown with the growth inhibitor during subsequent replanting into a standard Murashige and Skoog nutrient medium did not show a negative aftereffect.

\section{Conclusions}

Thus, we have established the best concentration of the growth inhibitor chlormequat chloride in the amount of 0.225 g per 1 liter of the Murashige and Skoog nutrient medium, which reduces the plants' height (up to $85.1 \%$ ), length (up to 15.0\%) and number of roots (up to 22.8\%), increases the number of internodes (up to $22.1 \%$ ) depending on the variety. The active substance makes it possible to lengthen cultivation period by 2.3 times and reduce the number of passages and, accordingly, reduce the cost of a set of measures for this work. 


\section{References}

1. S.V. Zhevora, B.V. Anisimov, E.A. Simakov, E.V. Oves, S.N. Zebrin, Agroinnovations, State and current problems of potato growing in Russia, 1 (1), 4-14 , (2019)

2. E.V. Oves, B.V. Anisimov, S.V. Zhevora, V.V. Boyko, N.A. Gaitova, N.A. Fenina, O.A. Shishkina, Agro-innovations, Potato seed production: practical experience, 2 (2), 10-17, (2019)

3. A.I. Uskov, D.V. Kravchenko, L.B. Uskova, P.A. Galushka, A.A. Zamyatnin, M.V. Skulachev, Agriculture, Regulation of physiological aging of potato culture, 8, 33-37, (2019)

4. D.V. Kravchenko, P.A. Galushka, Potatoes and vegetables, Consequence of Skulachev ions in vitro, 9, 24, (2015)

5. A. Badoni, A. Ahmad, A. Singh, A. Panwar, N. Chandra, H. Malhotra, J. S. Chauhan, International journal of science and nature, Effect of lowcost component culture media on the quality and yield of in vitro produced microtubers of potato, 7 (1), 190-193, (2016)

6. R.G. Butenko, Regulation of growth and development of potatoes, Some physiological problems in in vitro cultivation of potatoes, 88-97, (1990)

7. M. J. Moeini, Advances in environmental biology, Effects of different plant growth regulators and potting mixes on micro-propagation and mini-tuberization of potato plantlets, 5 (4), 631-638, (2011)

8. A.I. Uskov, Achievement of science and technology in agro-industrial complex, Reproduction of a healthy source material for potato seed production: obtaining source plants, 9, 20-22, (2009)

9. G.G. Mamaeva, Abstract journal, Plant growth regulators as a factor in reducing negative effect of pesticides. Environmental safety in the agro-industrial complex, 3, 732, (2002)

10. S. A. Buldakov, N. A. Shakleina, L. P. Plekhanova, V. A. Chuvilina, Research on crops, Scientific bases of improvement of potato seed system in Sakhalin region, 21, 78-81, (2020)

11. S.V. Maltsev, Agricultural biology, On the efficiency of treatment of potato seed tubers with ethylene, 56 (1), 44-53, (2021)

12. S.N. Timofeeva, Yu.V. Smolkina, N.V. Apanasova, O.I. Yudakova, Technology of in vitro micropropagation: a tutorial, (2016)

13. B.A. Dospekhov, Method of field experiment, (1979)

14. A. Nistor, G. Campeanu, N. Atanasiu, Romanian biotechnological letters, Influence of potato genotypes on «in vitro» production of microtubers, 15 (3), 5317-5324. (2010) 